\title{
PENGARUH PEMBERIAN PAKLOBUTRAZOL DAN PUPUK TERHADAP INDUKSI PEMBUNGAAN MANGGIS (Garcinia mangostana L.)
}

\section{THE EFFECT OF PACLOBUTRAZOL AND FERTILIZER TO INDUCTION FLOWERING MANGOSTEEN (Garcinia mangostana L.)}

\author{
Aprilia Widiatama $^{1}$, Agus Karyanto ${ }^{2}$, Rugayah ${ }^{2}$, dan Setyo Widagdo \\ ${ }^{1}$ Jurusan Agroteknologi, Fakultas Pertanian, Universitas Lampung, Bandar Lampung, Indonesia \\ ${ }^{2}$ Jurusan Agronomi dan Hortikultura Fakultas Pertanian, Universitas Lampung, Bandar Lampung, Indonesia \\ *Email: apriliawidiatama97@gmail.com \\ * Corresponding Author, Diterima: 3 Feb. 2021, Direvisi: 16 Mar. 2021, Disetujui: 3 Mei 2021
}

\begin{abstract}
Mangosteen (Garcinia mangostana L.) was a typical of tropical fruit and also the most export commodity. The production of the mangosteen in Indonesia was still low and productivity was not continuous, because there are several factors that influence it. One of them was the nature of flowering and fruiting of the mangosteen which was biennial bearing. Therefore, efforts should made to induce flowering of mangosteen off the season. The objective of research was to find an effective technology for induction of mangosteen flowering with the use of paklobutrazol and fertilizers. This research was conducted in Mulangmaya Village, Kota Agung Timur District, Tanggamus Regency at an altitude of $250 \mathrm{mdpl}$ from September 2018 to April 2019. Research method that to be used was Randomized Block Design (RBD) using a single factor with consisting of 3 treatments: $\left(K_{\theta}\right)$ without treatment, $\left(K_{p}\right)$ NPK Mutiara $1 \mathrm{~kg} /$ plant, paclobutrazol 2000 ppm, KNOá $20 \mathrm{~g} / \mathrm{l}$, and $\left(K_{2}\right)$ cow manure $10 \mathrm{~kg} / \mathrm{plant}$, NPK Mutiara $1 \mathrm{~kg} / \mathrm{plant}$, paclobutrazol $2000 \mathrm{ppm}$, KNOá $20 \mathrm{~g} / \mathrm{l}$. The data obtained were analyzed by analysis of variance and the median value was separated by orthogonal contrast test at the 5\% significance level. The results showed that the treatment of paklobutrazol and fertilizer could induce flowering of mangosteen compared to without treatment. The addition of cow manure $10 \mathrm{~kg} /$ plant with NPK $1 \mathrm{~kg} / \mathrm{plant}$, paclobutrazol 2000 ppm and KNOá $20 \mathrm{~g} / \mathrm{l}$ has the potential to increasing the number flowering mangosteen with a difference $(5,80 \%)$ and increasing the number of fruit per sample branch with a difference $(39,13 \%)$ when compared without using manure.
\end{abstract}

Keywords: Induction of mangosteen flowering, KNOá, NPK, paclobutrazol, and cow manure.

\begin{abstract}
ABSTRAK
Manggis (Garcinia mangostana L.) merupakan buah tropis dan termasuk komoditas ekspor unggulan. Produksi manggis di Indonesia masih tergolong rendah dan tidak kontinu, karena beberapa faktor yang mempengaruhinya, salah satunya yaitu sifat pembungaan dan pembuahan manggis yang bersifat biennial bearing. Oleh karena itu perlu dilakukan upaya untuk menginduksi pembungaan manggis di luar musim. Penelitian ini bertujuan untuk mendapatkan teknologi yang efektif untuk induksi pembungaan manggis dengan pengunaan paklobutrazol dan pupuk. Penelitian ini dilaksanakan di Desa Mulangmaya, Kecamatan Kota Agung Timur, Kabupaten Tanggamus pada ketinggian 250 mdpl dari bulan September 2018 hingga April 2019. Penelitian ini menggunakan Rancangan
\end{abstract}


Acak Kelompok (RAK) dengan faktor tunggal yang terdiri dari 3 perlakuan yaitu: $\left(\mathrm{K}_{0}\right)$ tanpa perlakuan, $\left(\mathrm{K}_{1}\right)$ NPK Mutiara 1 kg/tanaman, paklobutrazol 2000 ppm, KNOá $20 \mathrm{~g} / 1$, dan $\left(\mathrm{K}_{2}\right)$ pupuk kandang sapi $10 \mathrm{~kg} /$ tanaman, NPK Mutiara 1 kg/tanaman, paklobutrazol 2000 ppm, KNOá 20 g/l. Data yang diperoleh dianalisis dengan analisis ragam dan dilakukan pemisahan nilai tengah dengan uji orthogonal kontras pada taraf nyata 5\%. Hasil penelitian menunjukkan bahwa perlakuan paklobutrazol dan pupuk dapat menginduksi pembungaan manggis dibandingkan dengan tanpa perlakuan. Penambahan pupuk kandang sapi $10 \mathrm{~kg} / \operatorname{tanaman}, \mathrm{NPK} 1 \mathrm{~kg} / \tan a m a n$ dengan pemberian paklobutrazol 2000 ppm dan KNOá 20 g/l lebih berpotensi mempercepat pembungaan manggis dengan selisih (5,80 \%) dan meningkatkan jumlah buah per cabang sampel tertinggi dengan selisih $(39,13 \%)$ jika dibandingkan tanpa penambahan pupuk kandang.

Kata kunci : Induksi pembungaan manggis, KNOá, NPK, paklobutrazol, dan pupuk kandang sapi.

\section{PENDAHULUAN}

Tanaman manggis (Garcinia mangostana L.) berasal dari Asia Tenggara dan buahnya mendapat julukan Queen of Fruit. Manggis banyak disukai oleh masyarakat dunia karena memiliki banyak manfaat dan memiliki citarasa yang khas, yaitu perpaduan rasa manis, asam, dan sedikit sepat. Oleh karena itu, manggis merupakan salah satu komoditas ekspor buah-buahan bernilai ekonomi tinggi (Paramawati, 2010).

Menurut Badan Pusat Statistik (2013), Lampung merupakan salah satu Provinsi penghasil manggis di Indonesia. Pada tahun 2012 jumlah produksi manggis di Lampung sebesar 6.698 ton dan Kabupaten Tanggamus merupakan Kabupaten penghasil buah manggis terbesar di Provinsi Lampung dengan produksi mencapai 5.529 ton.

Produksi buah manggis tersebar di beberapa Kecamatan di wilayah Tanggamus seperti Wonosobo, Kota Agung Barat, dan Kota Agung Timur karena wilayah tersebut memiliki kondisi iklim dan ketinggian tempat yang cocok untuk pertumbuhan tanaman manggis. Salah satu wilayah yang memiliki perkebunan manggis berumur 20 tahun sampai berumur lebih dari 30 tahun adalah Desa Mulangmaya Kecamatan Kota
Agung Timur(Gambar 1). Menurut Dinas Tanaman Pangan dan Hortikultura (2013), produksi manggis tahun 2012 di Kota Agung Timur yaitu 20 ton dengan luas lahan 200 ha, sedangkan produksi manggis di Kota Agung Barat lebih tinggi dibandingkan dengan Kota Agung Timur yaitu 1.400 ton dengan luas lahan 180 ha. Perbedaan produksi pada lokasi yang berdekatan tersebut, menimbulkan dugaan bahwa pembungaan manggis memerlukan cuaca tertentu, yaitu adanya periode kering yang jelas selama beberapa minggu, sedangkan dalam kurun waktu tersebut lokasi Kota Agung Timurmengalami periode basah sepanjang tahun.

Produksi manggis mengalami fluktuasi dari tahun ke tahun yang disebabkan oleh beberapa faktor salah satunya yaitu akibat pembungaan manggis yang bersifat biennial bearing. Menurut Dennis dan Neilsen (1999), biennial bearing dapat terjadi karena buah muda memproduksi hormon giberelin yang ditranslokasikan ke bagian pucuk vegetatif sehingga pucuk akan tumbuh subur untuk membentuk daun dan tidak membentuk bunga pada tahun berikutnya.

Pengaruh hormon giberelin pada tanaman dapat diatasi dengan pemberian zat pengatur tumbuh yaitu Paklobutrazol. Menurut Widaryanto et al. (2011), 


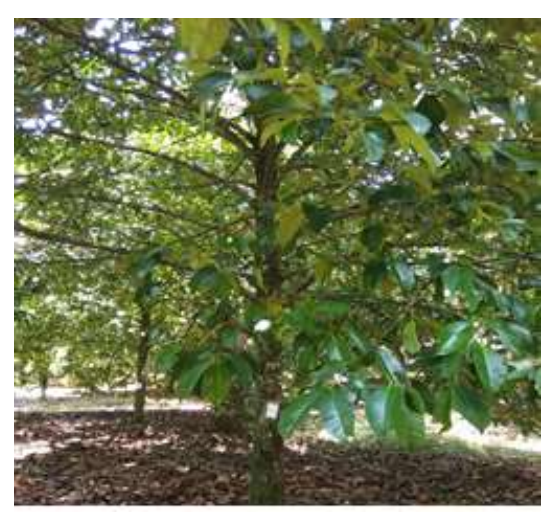

Gambar 1. Tanaman manggis

pemberian Paklobutrazol pada tanaman dapat menghambat biosintesis giberelin sehingga dapat menghambat pertumbuhan vegetatif dan memacu pertumbuhan generatiftanaman. Hal tersebut diperkuat dari hasil penelitian Rai et al. (2004) yang menunjukkan bahwa pemberian paklobutrazol $2 \mathrm{~g} /$ tanaman dapat menurunkan kandungan giberelin dan meningkatkan kandungan gula total dan $\mathrm{C} / \mathrm{N}$ ratio sehingga dapat menginduksi bunga manggis.

Pemberian Paklobutrazol ke tanaman dapat menyebabkan dormansi pada tunas generatifyang telah terinduksi karena meningkatnya biosintesis asam absisat, sehingga perlu dikombinasikan dengan zat pemecah dormansi. Hasil penelitian Poerwanto et al. (1997) menunjukkan bahwa KNOá dengan konsentrasi $20 \mathrm{~g} / \mathrm{l}$ dapat memecahkan tunas bunga yang dorman pada tanaman mangga Gadung setelah satu bulan aplikasi Paklobutrazol dengan dosis $2 \mathrm{~g} /$ pohon.

Upaya yang dapat dilakukan untuk menambah kandungan unsur hara dalam tanah untuk meningkatkan produksi tanaman manggis yaitu dengan pemberian pupuk organik maupun anorganik. Salah satu pupuk organik yang dapat digunakan yaitu pupuk kandang sapi. Menurut Lingga dan Marsono (2003), pupuk kandang sapi dapat memperbaiki sifat kimia tanah karena mengandung unsur hara makro seperti N,P, dan $\mathrm{K}$ serta mengandung unsur hara mikro seperti $\mathrm{Mn}, \mathrm{Fe}$, dan Zn. Selain itu, pupuk kandang dapat memperbaiki sifat fisik tanah, dan sifat biologi tanah sehingga tanaman dapat tumbuh baik dan dapat memberikan produksi yang tinggi, sedangkan salah satu pupuk anorganik yang dapat digunakan yaitu pupuk NPK Mutiara. Oleh karena itu, penelitian ini bertujuan untuk mengetahui pengaruh pemberian Paklobutrazol dan pupuk terhadap induksi pembungaan manggis.

\section{BAHAN DAN METODE}

Penelitian ini dilakukan pada bulan September 2018 hingga April 2019 di Kebun manggis petani Desa Mulangmaya, Kecamatan Kota Agung Timur, Kabupaten Tanggamus pada ketinggian 250 mdpl. Pada lokasi penelitian memiliki tekstur tanah lempung berpasir dengan $\mathrm{pH}$ tanah 5,54 yang tergolong masam, memiliki kandungan N-total 0,22\%, kandungan Ptersedia 4,65 ppm, C-organik 1,48\%, K-dd 0,22 me/ 100g, dan KTK 9,01 me/100g, dengan curah hujan $109-846 \mathrm{~mm} / \mathrm{bulan}$.

Alat-alat yang digunakan yaitu cangkul, sprayer, kantong plastik, meteran, tali rafia, ember, gunting, alat tulis, dan kamera. Bahan-bahan yang digunakan yaitu tanaman manggis berumur 20-30 tahun, pupuk kadang sapi, NPK Mutiara (16:16:16), paklobutrazol, KNOá, dan air. Penelitian ini dilakukan menggunakan Rancangan Acak Kelompok (RAK) yang terdiri dari 3 perlakuan yaitu: $\mathrm{K}_{0}$ (tanpa perlakuan), $\mathrm{K}_{1}\left(\mathrm{NPK}+\right.$ paklobutrazol+KNOá), dan $\mathrm{K}_{2}$ (Pupuk kandang sapi+NPK+paklobutrazol+KNOá) 
yang diulang sebanyak 5 kali dan setiap ulangan terdiri dari 3 sampel per cabangan yang diamati.

Pemberian pupuk kandang sapi $10 \mathrm{~kg} /$ tanaman dan NPK 1 kg/tanaman dilakukan dengan cara ditabur pada lubang yang melingkari kanopi tanaman dengan jarak $1 \mathrm{~m}$ dari batang pohon yang diaplikasikan pada saat awal penelitian. Konsentrasi paklobutrazol yang digunakan yaitu 2000 ppm dengan cara pembuatan melarutkan Goldstar (25\% paklobutrazol) sebanyak 8 $\mathrm{ml}$ sehingga volumenya menjadi 1 liter. Penjelasan perhitungan paklobutrazol dicantumkan pada lampiran. Aplikasi paklobutrazol dilakukan dengan cara disiram pada daerah perakaran tanaman setelah satu bulan aplikasi pupuk.

Aplikasi KNOá dengan konsentrasi 20 g/l diberikan setelah satu bulan aplikasi Paklobutrazol. KNOá diberikan ke tanaman dengan cara disemprotkan dari tajuk bagian atas menggunakan knapsack sprayer dengan volume semprot 5 liter/ tanaman. Pengamatan dilakukan sejak 0, 4, 21, dan 29 minggu setelah aplikasi. Variabel vegetatif yang diamati yaitu, panjang cabang utama, jumlah daun, dan lingkar pangkal cabang, sedangkan variabel generatif yang diamati yaitu, waktu muncul bunga, dan jumlah buah per cabang sampel.

Data yang diperoleh pada setiap percobaan dilakukan analisis ragam dan dilanjutkan dengan uji orthogonal kontras pada taraf nyata $5 \%$ untuk mengetahui respon tanaman manggis terhadap perlakuan yang diterapkan.

\section{HASIL DAN PEMBAHASAN}

\section{Pertumbuhan fase vegetatif}

Hasil uji orthogonal kontras pada 29 minggu setelah aplikasi menunjukkan bahwa perlakuan Paklobutrazol dan pupuk menurunkan panjang cabang utama dan meningkatkan lingkar pangkal cabang, namun tidak mempengaruhi jumlah daun (Tabel 1). Tanaman yang tidak diberi perlakuan memiliki panjang cabang utama terpanjang $(26,08 \mathrm{~cm})$, dengan selisih 28,09\% dibandingkan cabang yang diberi perlakuan (20,36 cm). Pemberian pupuk kandang menghasilkan

Tabel 1. Hasil uji orthogonal kontras pengaruh pemberian paklobutrazol dan pupuk terhadap panjang cabang utama, jumlah daun, dan lingkar pangkal cabang manggis 29 minggu setelah aplikasi.

\begin{tabular}{|c|c|c|c|c|}
\hline \multirow{2}{*}{ Pembanding } & \multicolumn{4}{|c|}{ Panjang Cabang Utama } \\
\hline & Nilai pengamatan & Selisih & \%Selisih & F-hitung \\
\hline $\mathrm{P} 1: \mathrm{K}_{0} \mathrm{vs} \mathrm{K}_{1} \& \mathrm{~K}_{2}$ & 26,08 vs 20,36 & 5,72 & 28,09 & $17,29^{*}$ \\
\hline $\mathrm{P} 2: \mathrm{K}_{1}$ vs $\mathrm{K}_{2}$ & 22,86 vs 17,86 & 5,00 & 28,00 & $9,91^{*}$ \\
\hline \multirow{2}{*}{ Pembanding } & \multicolumn{4}{|c|}{ Jumlah Daun } \\
\hline & Nilai pengamatan & Selisih & $\%$ Selisih & F-hitung \\
\hline $\mathrm{P} 1: \mathrm{K}_{0}$ vs $_{1} \& \mathrm{~K}_{2}$ & 18,80 vs 15,70 & 3,10 & 19,75 & $4,06^{\text {tn }}$ \\
\hline $\mathrm{P} 2: \mathrm{K}_{1}$ vs $\mathrm{K}_{2}$ & 17,40 vs 14,00 & 3,40 & 24,29 & $3,67^{\mathrm{tn}}$ \\
\hline \multirow{2}{*}{ Pembanding } & \multicolumn{4}{|c|}{ Lingkar Pangkal Cabang } \\
\hline & Nilai pengamatan & Selisih & $\%$ Selisih & F-hitung \\
\hline $\mathrm{P} 1: \mathrm{K}_{0} \mathrm{vs} \mathrm{K}_{1} \& \mathrm{~K}_{2}$ & 3,07 vs 3,55 & $-0,48$ & 13,53 & $6,68^{*}$ \\
\hline $\mathrm{P} 2: \mathrm{K}_{1} \mathrm{vs} \mathrm{K}_{2}$ & 3,53 vs 3,57 & $-0,04$ & 1,12 & $0,03^{\text {tn }}$ \\
\hline
\end{tabular}

Keterangan: $\mathrm{K}_{0}=$ tanpa perlakuan; $\mathrm{K}_{1}=$ paklobutrazol $+\mathrm{NPK}+\mathrm{KNO}_{3} ; \mathrm{K}_{2}=$ pupuk kandang + paklobutrazol $+\mathrm{NPK}+\mathrm{KNO}$; tn $=$ tidak berbeda nyata pada taraf $5 \% ; *=$ berbeda nyata pada taraf $5 \%$. 
cabang terpendek $(17,86 \mathrm{~cm})$ dibandingkan cabang yang tidak diberi pupuk kandang $(22,86 \mathrm{~cm})$. Pemendekan panjang cabang utama pada tanaman yang diberi perlakuan diikuti dengan peningkatan lingkar pangkal cabang yang berbeda nyata dengan tanaman tanpa perlakuan.

Panjang cabang utama manggis yang diberi perlakuan paklobutrazol lebih pendek dibandingkan dengan panjang cabang yang tidak diberi paklobutrazol. Hal ini sesuai dengan hasil penelitian Wahyuni (2005), perlakuan paklobutrazol pada tanaman durian dapat menekan pemanjangan tunas dibandingkan tanpa perlakuan paklobutrazol. Menurut Krishnamoorty (1981), cara kerja paklobutrazol yaitu dengan cara menghambat biosintesis giberelinyang dapatmenyebabkan terhambatnya pemanjangan sel pada meristem sub apikal sehingga pemanjangan tunas juga terhambat.

Hasil uji orthogonal kontras pada 29 minggu setelah aplikasi menunjukkan bahwa pemberian perlakuan paklobutrazol dan pupuk nyata meningkatkan lingkar pangkal cabang dibandingkan dengan tanpa perlakuan. Tanaman yang tidak diberi perlakuan memiliki lingkar cabang terkecil $(3,07 \mathrm{~cm})$ dengan selisih 13,53\% dibandingkan lingkar cabang yang diberi perlakuan $(3,55 \mathrm{~cm})$, namun tidak berbeda nyata terhadap pemberian penambahan pupuk kandang dengan tanpa pupuk kandang (Tabel 1). Pertambahan lingkar pangkal cabang manggis yang diberi perlakuan paklobutrazol lebih besar dibandingkan dengan lingkar cabang yang tidak diberi paklobutrazol. Hal ini sesuai dengan hasil penelitian Bowo (2018), bahwa pemberian paklobutrazol 0,9 $\mathrm{ml} /$ tanaman dapat meningkatkan diameter batang jambu air dibandingkan dengan 0 ml/tanaman. Menurut Widaryanto et al. (2011), pemberian paklobutrazol dapat menekan pertumbuhan batang tanaman sehingga diameter batang bertambah tebal. Penebalan batang disebabkan oleh adanya peningkatan volume sel parenkim di daerah korteks serta meningkatnya produksi sel di daerah kambium akibat pemberian paklobutrazol.

\section{Pertumbuhan fase generatif}

Hasil uji orthogonal kontras pada 29 minggu setelah aplikasi menunjukkan bahwa pemberian perlakuan paklobutrazol dan pupuk dapat mempercepat waktu muncul bunga dan meningkatkan jumlah buah per cabang sampel (Tabel 2). Tanaman

Tabel 2. Hasil uji orthogonal kontras pengaruh pemberian paklobutrazol dan pupuk terhadap waktu muncul bunga dan jumlah buah per cabang manggis 29 minggu setelah aplikasi.

\begin{tabular}{|c|c|c|c|c|}
\hline \multirow{2}{*}{ Pembanding } & \multicolumn{4}{|c|}{ Waktu muncul bunga } \\
\hline & Nilai pengamatan & Selisih & \%Selisih & F-hitung \\
\hline $\mathrm{P} 1: \mathrm{K}_{0}$ vs $\mathrm{K}_{1} \& \mathrm{~K}_{2}$ & 166,00 vs 142,00 & 24,00 & 16,90 & $8384,98^{*}$ \\
\hline $\mathrm{P} 2: \mathrm{K}_{1}$ vs $\mathrm{K}_{2}$ & 146,00 vs 138,00 & 8,00 & 5,80 & $698,75^{*}$ \\
\hline \multirow{2}{*}{ Pembanding } & \multicolumn{4}{|c|}{ Jumlah buah per cabang sampel } \\
\hline & Nilai pengamatan & Selisih & \%Selisih & F-hitung \\
\hline P1: $\mathrm{K}_{0}$ vs $\mathrm{K}_{1} \& \mathrm{~K}_{2}$ & 1,60 vs 3,70 & $-2,10$ & 56,76 & $106,10^{*}$ \\
\hline $\mathrm{P} 2: \mathrm{K}_{1}$ vs $\mathrm{K}_{2}$ & 2,80 vs 4,60 & $-1,80$ & 39,13 & $58,46^{*}$ \\
\hline
\end{tabular}

Keterangan: $\mathrm{K}_{0}=$ tanpa perlakuan; $\mathrm{K}_{1}=$ paklobutrazol $+\mathrm{NPK}+\mathrm{KNO}_{3} ; \mathrm{K}_{2}=$ pupuk kandang + paklobutrazol $+\mathrm{NPK}+\mathrm{KNO} 3$; tn $=$ tidak berbeda nyata pada taraf $5 \% ; *=$ berbeda nyata pada taraf $5 \%$. 
yang tidak diberi perlakuan waktu muncul bunganya lebih lama (166,00 hari) dengan selisih sebesar 16,90 $\%$ dengan yang diberi perlakuan (142 hari). Pemberian pupuk kandang waktu muncul bunganya lebih cepat (138,00 hari) dengan selisih 5,80 \% dibandingkan dengan yang tidak diberi pupuk kandang (146,00 hari).

Tanaman manggis membutuhkan periode kering untuk menginduksi pembungaan. Menurut hasil penelitian Apiratikorn et al. (2012) tanaman manggis di Thailand Selatan membutuhkan periode kering sekitar 21 hari untuk menginduksi pembungaan diikuti dengan irigasi atau curah hujan. Menurut Yaacob dan Tindall (1995) bahwa tanaman manggis memerlukan periode kering singkat (15-30 hari) untuk memacu munculnya bunga diikuti oleh irigasi atau curah hujan. Namun, pada saat penelitian berlangsung pada bulan September - Desember 2018 intensitas curah hujan sangat tinggi terutama pada bulan November yaitu 846 $\mathrm{mm}$, sehingga induksi pembungaan manggis terhambat. Periode berbuah terjadi di bulan April 2019 dengan intensitas curah hujan yaitu $195 \mathrm{~mm}$. Menurut Setiawan et al. (2012) pohon manggis di Jawa Barat pada tahun 2009 secara teratur menghadapi masa kekeringan dari bulan Juli-Agustus, diikuti dengan periode berbunga dari bulan September - Oktober. Pada tahun 2010, pola fenologi pohon manggis berubah nyata karena

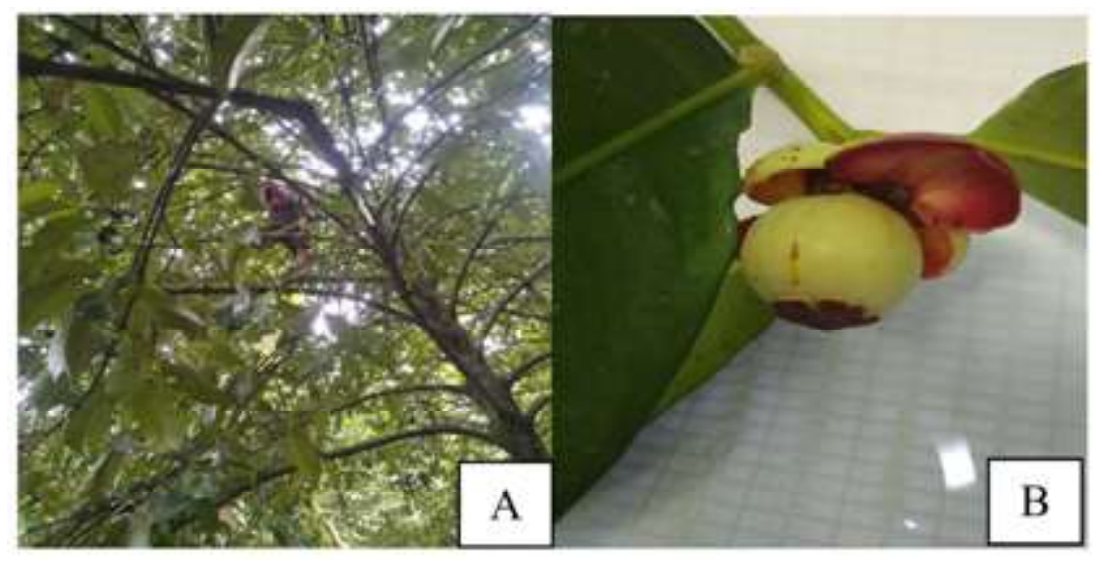

Gambar 2. Tanaman manggis tanpa perlakuan (A), buah manggis tanpa perlakuan (B)

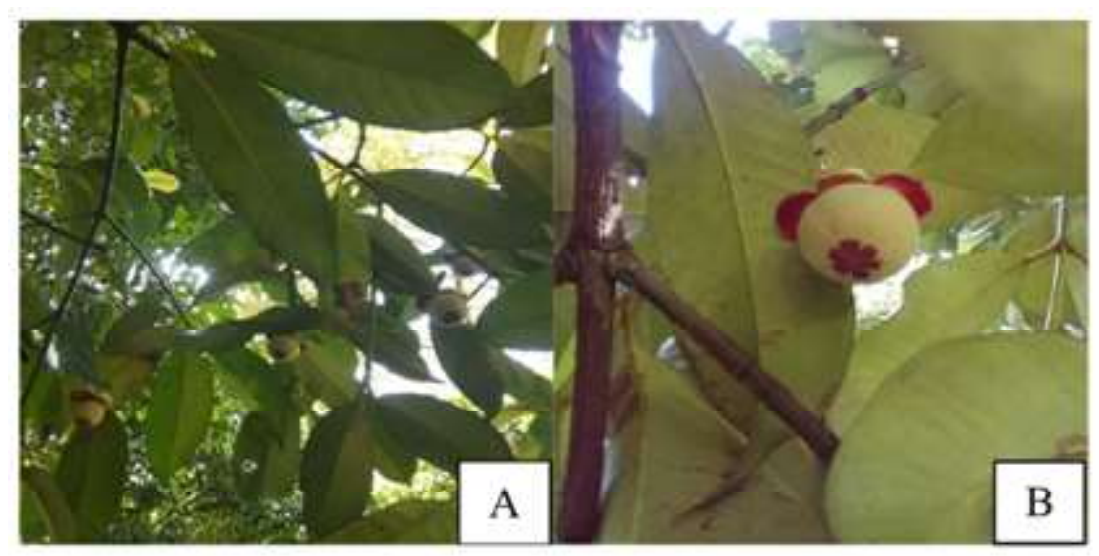

Gambar 3. Tanaman manggis perlakuan $\mathrm{K}_{1}(\mathrm{~A})$, buah manggis $\mathrm{K}_{1}(\mathrm{~B})$ 
curah hujan yang tidak teratur, sehingga terjadi kekeringan pada bulan April dan menginduksi pembungaan maggis di bulan Mei.

Berdasarkan hasil uji orthogonal kontras pada 29 minggu setelah aplikasi menunjukkan bahwa pemberian perlakuan paklobutrazol dan pupuk meningkatkan jumlah buah per cabang sampel dibandingkan tanpa perlakuan. Tanaman yang tidak diberi perlakuan menghasilkan jumlah buah per cabang sampel yang sedikit (1,60 buah) (Gambar 2) dengan selisih sebesar $56,76 \%$ dengan yang diberi perlakuan (3,70 buah). Pemberian pupuk kandang menghasilkan jumlah buah per cabang sampel lebih banyak $(4,60$ buah) dengan selisih 39,13\% (Gambar 4) dibandingkan dengan yang tidak diberi pupuk kandang (2,80 buah) (Gambar 3). Hal ini sesuai dengan hasil penelitian Sumantra et al. (2010), bahwa perlakuan pupuk kandang $10 \mathrm{~kg} /$ tanaman, NPK $2 \mathrm{~kg} / \operatorname{tanaman}$, Greener $2 \mathrm{ml} /$ liter dengan pemberian paklobutrazol $2 \mathrm{~g} /$ tanaman, dan $\mathrm{KNO}_{3} 20$ g/l secara nyata dapat mempercepat waktu munculnya bunga manggis di Bali jika dibandingkan dengan tanpa perlakuan paklobutrazol dan KNOá yaitu 56 HSP dan 93 HSP, serta menghasilkan jumlah buah manggis per cabang sampel yang lebih banyak dibandingkan dengan tanpa perlakuan paklobutrazol dan KNOá yaitu 18,86 buah dan 9,53 buah.

\section{KESIMPULAN}

Berdasarkan hasil penelitian, diperoleh kesimpulan bahwa, perlakuan paklobutrazol dan pupuk dapat menginduksi pembungaan manggis dibandingkan tanpa perlakuan. Penambahan pupuk kandang sapi 10 $\mathrm{kg} /$ tanaman, NPK 1 kg/tanaman dengan pemberian paklobutrazol 2000 ppm dan KNOá 20 g/l lebih berpotensi mempercepat pembungaan manggis dengan selisih (5,80\%) dan meningkatkan jumlah buah per cabang sampel tertinggi dengan selisih (39,13\%) jika dibandingkan tanpa penambahan pupuk kandang.

\section{DAFTAR PUSTAKA}

Apiratikorn, S., Sdoodee, S., Lerslerwong, L., and Rongsawat, S. 2012. The impact of climatic variability on phenological change, yield and fruit quality of mangosteen in Phatthalung Province, Southern Thailand. Kasetsart J. (Nat. Sci.) $46: 1-9$.

Badan Pusat Statistik. 2013. Lampung Dalam Angka. BPS Provinsi Lampung. $421 \mathrm{hlm}$.

Bowo, B.T. 2018. Pengaruh Pemberian Pupuk Organik Cair (POC) Urin kambing dan Hormon Paclobutrazol terhadap Pertumbuhan Jambu Air Madu Deli (Syzgiumaqueum Burn. F). (Skripsi). Universitas Muhammadiyah Sumatera Utara. Medan. $50 \mathrm{hlm}$.

Dennis, F.P. dan J.C. Neilsen. 1999. Physiological factors effecting biennial bearing in tree fruit: The role of seed in apple. Hort. Technology 9 (3) : 317-322.

Dinas Tanaman Pangan dan Hortikultura. 2013. Angka Perhitungan Tahunan. Dinas Tanaman Pangan dan Hortikultura Kabupaten Tanggamus. Bandar Lampung.

Krishnamoorthy. 1981. Plant Growth Substances Including Application In Agriculture. Tata Mc Graw-Hill Pub. Co. Ltd. New Delhi. $214 \mathrm{p}$. 
Lingga, P. dan Marsono. 2003. Petunjuk Penggunaan

Pupuk. PT Penebar Swadaya. Jakarta. $150 \mathrm{hlm}$.

Paramawati, R. 2010. Dahsyatnya Manggis untuk Menumpas Penyakit. Agromedia Pustaka. Jakarta. 102 hlm.

Poerwanto R, Efendi, D. dan Harjadi, S.S. 1997. Pengaturan pembungaan mangga Gadung 21 di luar musim dengan paklobutrazol dan zat pemecah dormansi. J. Hayati 4(2):41-46.

Rai, I.N., Poerwanto, R., Darusman, L.K., dan Purwoko, B.S. 2004. Pengaturan pembungaan tanaman manggis (Garcinia mangostana L.) di luar musim dengan strangulasi, serta aplikasi paklobutrazol dan etepon. Bul.Agron. 32 (2) : 12-20.

Setiawan, E., Poerwanto, R., Fukuda, F., and Kubota, N. 2012. Meterological conditions of mangosteen Orchard in West Java, Indonesia and Seasonal changes in C-N Ratio of their leaves as affected by sector (position in canopy) and tree age. Scientific Reports of the Faculty of Agriculture. Okayama University 101: 39-47.
Sumantra, I.K., Wiswasta, IGN.A., Sujana, I.P., dan Widnyana, I.K. 2010. Peningkatan produksi dan pendapatan petani manggis melalui penerapan teknologi pembuahan manggis di luar musim di Selemadeg Tabanan. Majalah Aplikasi Ipteks Ngayah. 1(1):71-80.

Wahyuni, R. D. 2005. Pengaruh Aplikasi Paklobutrazol dan KNOá terhadap Pertumbuhan dan Pembungaan Durian (Durio zibethinus Murr.) Cv. Montong. (Skripsi). Institut Pertanian Bogor. Bogor. $46 \mathrm{hlm}$.

Widaryanto, E., Baskara, M., dan Suryanto, A. 2011. Aplikasi Paklobutrazol pada tanaman bunga matahari (Helianthus annuus L. cv. Teddy Bear) sebagai upaya menciptakan tanaman hias pot. Perhorti Indonesia. Lembang 23-24 November 2011. $12 \mathrm{hlm}$.

Yacoob, O. and Tindall, H.D. 1995. Mangosteen Cultivation. FAO Plant Production and protection paper 129. Brussels: FAO Plant Production and Protection Division of the United Nations, Belgium. $100 \mathrm{hlm}$. 